\title{
TRAVESSIAS IDENTITÁRIAS: REPRESENTAÇÕES DOS REFUGIADOS EM MACAU NA OBRA de Rodrigo Leal de Carvalho ${ }^{1}$
}

CROSSING IDENTITIES: REPRESENTATIONS OF REFUGEES in MaCau in RoDRIGo LEAL DE CARVALHO'S WORKS

\author{
Dora Nunes Gago \\ Universidade de Macau \\ Macau - China \\ ORCID 0000-0002-6300-1575
}

\begin{abstract}
Resumo
Este artigo explora as representaçóes dos refugiados e apátridas nos romances de Rodrigo Leal de Carvalho: Requiem para Irina Ostrakoff (1993) e A Mãe (2001). Atendendo aos contributos teóricos de Hall, Leerssen, Said, Arendt, Hamon, entre outros, analisaremos o modo como a condição e a identidade do refugiado apátrida são representadas num discurso de contornos realistas, através da criação de personagens "vivas", verossímeis, e de alguns ecos de uma "comédia humana" (na linha de Balzac), transposta para o pequeno espaço longínquo de Macau.
\end{abstract}

Palavras-chave: refugiados; nação; exílio; identidade; Macau; realismo.

\begin{abstract}
This article explores the representations of refugees and stateless persons in Rodrigo Leal de Carvalho's novels: Requiem para Irina Ostrakoff (1993) and $A$ Mãe (2001). Grounded on the theories of Hall, Leerssen, Said, Arendt and Hamon, among others, our aim is to analyse the way in which the condition and identitity of stateless refugees are represented in a realist discourse by creating credible characters and by somehow echoing the "human come-
\end{abstract}

\section{Resumen}

Este artículo explora las representaciones de los refugiados y apátridas en las novelas de Rodrigo Leal de Carvalho tituladas Requiem para Irina Ostrakoff (1993) y A Mãe (2001). Bajo los presupuestos teóricos de Hall, Leerssen, Bhabha, Said, Hamon, entre otros, nuestro objetivo es analizar la manera cómo la condición y la identidad de los refugiados apátridas son representadas en un discurso realista, a través de la creación de personajens verosímiles y

1 Este artigo foi realizado no âmbito da MYRG2017-00015-FAH (Narrating the exile in Portuguese), financiada pela Universidade de Macau (China). 
dy" (along Balzac's lines), which has been transposed to Macau, a small and distant place.

Keywords: refugees; nation; exile; identity; Macau; realism. de algunos ecos de la "comedia humana” renovada y transplantada para el pequeño y lejano espacio de Macau.

Palavras claves: refugiados; nación; exilio; identidad; Macau; realismo.

\section{Introdução}

Num mundo assolado por problemas e questôes relacionadas com a imigração e com a problemática dos refugiados, ler a obra de Rodrigo Leal de Carvalho² (1932-), autor português até ao momento muito pouco conhecido no panorama da literatura portuguesa, permite-nos mergulhar noutras crises migratórias com alguns contornos semelhantes, ocorridas no espaço sui generis, denso e rico de Macau, território alcandorado no Sul da China, desde 1557 até 1999 sob administração portuguesa. Macau é o espaço privilegiado de cruzamento de povos e de culturas, ou, como refere Leal de Carvalho (2015, p. 19), "Fadado (ou condenado), pela sorte ou pela geopolítica, a cadinho de culturas e etnias, o minúsculo enclave acabou por ser um porto de abrigo para gentes de mundos vários que aqui vieram parar por desvairadas razóes [...]". Estas palavras espelham a importância de Macau como espaço de convergência de povos deslocados, pelas mais diversas razóes. É precisamente o deslocamento a força motriz de Requiem para Irina Ostrakoff(1993) e de A Mãe (2001), dois dos oito romances publicados por Leal de Carvalho ${ }^{3}$, que servem de base ao presente estudo. Duas obras que dialogam entre si, por terem como protagonistas refugiados russos apátridas - que, inclusive, se entrecruzam em $A$ Mãe, aquando do exílio em Xangai - e pelo contexto histórico-social que abordam, cobrindo o tempo cronológico que

2 Nascido na Praia da Vitória (Açores), a 20 de Novembro de 1932, Rodrigo Leal licenciou-se em Direito pela Universidade de Lisboa, tendo ingressado a seguir na Magistratura. Chegou a Macau em 1959, como Delegado do Ministério Público, tendo sido depois Procurador da República e Presidente do Tribunal de Contas. Neste território, se foi fixando até à passagem para a administração chinesa, em 1999, com diversos interregnos (de aproximadamente oito anos) para exercer funçôes na Guiné-Bissau, Angola e Moçambique. (SENA, 2010, p. 276-277)

3 Sobre o autor e a sua obra, veja-se Blayer e Gago (2016, p. 111-124). 
se estende desde "a belle époque", cruzando a Guerra do Pacífico, a Primeira e Segunda Grande Guerra Mundial, até aos sessenta do século XX.

Requiem para Irina Ostrakoff, o primeiro romance de Leal de Carvalho, foi distinguido com o Prémio Camilo Pessanha (atribuído pelo Instituto Português do Oriente). Editado em 1993, com uma 2a edição em 1995 e uma terceira em 2015, foi traduzido para chinês e búlgaro. A narrativa tem como ponto de partida a morte de Irina Ostrakoff, ocorrida durante uma cerimónia no Consulado de Inglaterra, para depois recuar aos anos da sua adolescência e formação, cruzando tempos e espaços que se estendem desde a Rússia czarista, passando por Xangai, para culminar numa "descida aos infernos" com o drama dos refugiados em Macau.

Por seu turno, $A$ Mãe inspira-se em factos ocorridos em Macau no pós-guerra do Pacífico, narrando a hercúlea saga de Natasha Korbachenko. Nascida na Sibéria, exilada para a Manchúria devido à revolução bolchevista, Natasha parte depois para Xangai, onde sobrevive dedicando-se à prostituição. Acaba por conhecer um estudante russo judeu (Vassili Yakovitch) com quem casa e tem cinco filhos. No momento em que Vassili se torna professor numa instituição de ensino superior em Xangai e a família atingira alguma estabilidade, eclode a guerra do Pacífico, sendo Xangai ocupada pelos japoneses, que iniciam uma dura perseguição contra os judeus. A família Yakovitch foge para Macau, onde sobrevive muito precariamente, enquanto aguarda a chegada de um visto de entrada nos Estados Unidos como imigrantes. Contudo, no final da guerra, todos os vistos para entrada da família nos Estados Unidos são aprovados, menos o do filho Ivan, por ser deficiente mental. Sáo então assolados pelo terrível dilema entre desistir do sonho americano ou abandonar o filho em Macau.

O nosso percurso hermenêutico realizar-se-á em duas fases. Primeiramente, analisaremos a configuração das personagens num contexto histórico determinado, através de um discurso de marcas realistas (atendendo aos pressupostos teóricos de Philip Hamon, entre outros), que as torna verossímeis, figuradas de forma profundamente humanizada, espelhando alguns resquícios da "comédia humana" de Balzac no modo como reaparecem nas obras. Posto isto, centrar-nos- 
-emos no modo como a evolução das identidades das refugiadas será representada num cenário de exílio particular e sui generis: Macau.

\section{"Da Rússia sem amor" - a construção das personagens e o "efeito de real"}

A inspiração no "real" de onde emergem as duas narrativas é evidenciada de modo diferente no início de cada uma delas. Assim, em Requiem para Irina Ostrakoff encontramos inicialmente um narrador homodiegético, conotado com o autor textual - que apenas volta a surgir no último capítulo -, e cuja função é acompanhar a execução das diligências legais referentes ao espólio de Irina (CARVALHO, 2015 , p. 26). A seguir, surge um segundo narrador, o Dr. Remédios, macaense, que cederá, por sua vez, lugar a um narrador omnisciente. Nesta esteira, “[...] joga-se, aliás, com uma multiplicação de espelhos que desdobram a figura do narrador e, mais uma vez, perturbam o estatuto entre a ficção realista e reflexão recitativa" (LABORINHO, 2015, p. 14).

Por seu turno, em A Mãe é apresentada uma explicação preliminar que visa aguçar a curiosidade do leitor, referindo-se que, embora seja uma obra de ficção, é "inspirada numa ocorrência verificada em Macau, no post guerra do Pacífico [...]” (CARVALHO, 2001, p. 5). Deste modo, em ambos os incipit se nota uma "autenticação" do acto narrativo que pretende instaurar no leitor um horizonte de expectativas realista, criando, desde o início, o "efeito do real" (HAMON, 1982, p. 150). Por outro lado, é realçada a importância da "narração de histórias". Aliás, no prefácio de Requiem para Irina Ostrakoff, o primeiro narrador homodiegético assume-se directamente como "contador de histórias", declarando que "a verdade dos factos é depois composta pela imaginação” (CARVALHO, 2015, p. 20). Evidencia-se, deste modo, a evocação do gesto ancestral da narração de histórias que, de acordo com Fulford (1991, p. 1), corresponde ao início da vida da narrativa na Terra ${ }^{4}$. Fulford, citando Mc Carty, acrescenta ainda que Tolstói, Flaubert, Proust e outros grandes romancistas se dirigiram aos leitores como vizinhos dispostos a relatar um escândalo (1991,

4 "No doubt narrative began its life on earth in the formo $\mathrm{f}$ gossip, simples tories told by one individual to another" (FULFORD, 1991, p. 1). 
p. 2). É este tom de proximidade e de familiaridade com o intuito de atrair a atenção que observamos no início dos romances de Leal de Carvalho - e que imediatamente nos impele à continuação da leitura.

Tanto Requiem para Irina Ostrakoff como A Mãe principiam com uma morte - no primeiro caso da protagonista, no segundo de Ivan, o filho preferido de Natasha. Procede-se, posteriormente, a uma analepse (ou flash back) que, de acordo com Hamon (1982, p. 135), é um dos procedimentos que assegura a coerência global do discurso realista. Esse recuo temporal vai desvendando todo o percurso anterior das personagens, os factores que as impeliram à situação de exiladas apátridas e os atribulados caminhos que percorreram para sobreviver em Macau, o espaço fulcral da acção. Ao longo das narrativas, vão-se multiplicando as técnicas instauradoras do já referido "efeito de real". Antes de mais, observamos o enquadramento do passado, inscrito num tempo histórico determinado, sendo a análise psicológica das personagens empreendida cuidadosamente. Como aliás refere Bersani (1982, p. 49), "Dans la littérature realiste, les comportements sont l'expression continuelle de la psychologie des personnages". Assim, os comportamentos e as atitudes, tal como os incidentes aparentemente fortuitos, tudo contribui para uma caracterização mais verosímil das personagens e dos seus modos de agir.

Nesta esteira, em Requiem para Irina Ostrakoff, é descrita a ascendência da protagonista, oriunda de uma família aristocrata russa, neta dos condes de Orkoff, cuja infância e adolescência foram passadas no palácio de Odessa, educada por preceptoras e professores privados e pelos avós após a prematura morte dos pais. Esta caracterização do meio familiar funciona como elemento de ancoragem realista, fornecendo-nos uma "gramática da personagem" (HAMON, 1982, p. 136), que nos permitirá uma mais profunda e coerente legibilidade do seu comportamento. Outro elemento instaurador do real na ficção é a caracterização do contexto histórico que ilumina as diversas peripécias que se vão desenrolando, preparando o leitor para a sua interpretação. Além disso, evidencia-se um tom crítico perante as desigualdades sociais. É realçado o abismo existente na Rússia entre a pobreza do povo e a riqueza faustosa da aristocracia, no período que antecedeu a revolução bolchevista. Enquanto o povo se amontoava nas ruas, resplandecia a riqueza do palácio dos Condes Orkoff, onde "Os 
lustres e os candelabros fulguravam, reflectidos nos elegantes espelhos de Veneza; a música brotava, escolhida, em cascatas de melodia; e a juventude dourada de Odessa dançava e divertia-se" (CARVALHO, 2015, p. 102).

$\mathrm{Na}$ verdade, o requinte e o glamour desse ambiente vão posteriormente acentuar o contraste com o drama da miséria em que Irina, mais tarde, mergulhará. É-nos relatado o casamento de Irina com Igor Ostrakoff, oficial do exército do czare, a esplendorosa lua de mel a bordo do iate dos condes, numa viagem pela Europa. Corre o ano de 1914, e o narrador salienta a "cegueira" da felicidade do casal "[...] cegos para as outras nuvens ameaçadoras e negras que se acastelavam pelos céus da Europa" (CARVALHO, 2015: 121). Com efeito, o plano da História irrompe frequentemente na narrativa para revelar a alienação das personagens face ao "Outro" e ao mundo que habitam, quando a Primeira Guerra Mundial está prestes a eclodir. Não obstante, tal como nota Brookshaw (2002, p. 128), as personagens serão profundamente influenciadas pelas circunstâncias históricas. Aliás, a crítica à insensibilidade das personagens perante o fluir da história transparece: "Pouco dados à História e à Política, não prestaram atençáo às tensôes europeias nem à conturbada situação balcânica; de resto, os sérvios, os bósnios, os croatas, os montenegrinos e os outros andavam permanentemente à bulha entre si; não era novidade". (CARVALHO, 2015, p. 126-127). Assim, é criticada a atitude egocêntrica da classe social privilegiada que habita a sua "torre de marfim", concedendo uma vaga e preconceituosa "desatençáa" ao "Outro", já que consideram "normal" a existência de guerras entre os povos limítrofes. Por isso, é profundo o choque quando chegam as notícias da guerra na Rússia, "[...] e os nomes de Aleksandr Kerensky, Leon Trostsky e Vladimir Lenine entraram no léxico diário" (CARVALHO, 2015, p. 136). Os problemas económicos surgem, e Igor começa a trabalhar num hotel, recebendo posteriormente uma proposta de trabalho para Xangai, que aceita. Inicia-se, entấo, a primeira fase da saga do exílio. Ao contrário do que sucede frequentemente com os heróis realistas que viajam para perto do seu meio (HAMON, 1982, p. 137), o destino, neste caso, é distante e exótico. Entâo, sáo descritos os preparativos para a partida e a tentativa de preservar os elementos essenciais que garantam a preservação da memória: 
Regularizados os papéis que o estatuto de refugiados impunha, Irina embalou o pouco que ainda possuía, guardou cuidadosamente as fotografias familiares que trouxera consigo, olhou com carinho o belo solitário de que sempre recusara desfazer-se e foi acender uma vela em memória dos avós, na igreja russa de Paris. (CARVALHO, 2015, p. 144)

Neste caso, evidencia-se a importância da memória e a tentativa de a protagonista transportar consigo o passado materializado nas fotografias. Além disso, o anel, o belo solitário herdado, estabelecerá, ao longo da narrativa, um elo de pertença a um passado que alicerça a identidade de Irina. Esse anel será mantido por ela a todo o custo, mesmo nos momentos de maior dificuldade e, muito ironicamente, após a sua morte será resgatado pelo marido como oferta para a futura esposa. No excerto anteriormente apresentado, transparece a súbita mudança do estatuto das personagens, que passam de meros turistas em lua-de-mel para exilados refugiados. Nesta sequência, Edward Said (2003, p. 53), em Reflexóes sobre o Exílio, esboça uma definição de expatriados, emigrados, "exilados" e de "refugiados", interessando-nos, neste caso, as duas últimas categorias. Assim, o que marca um exilado é precisamente a sua impossibilidade de regresso à terra natal - o que sucede, indubitavelmente, com as protagonistas de $R e$ quiem e de A Mãe. Por seu turno, segundo Said, o termo "refugiado" tem uma conotação política, tendo sido uma "criação do Estado do século XX", sugerindo deslocaçóes massivas de gente que necessitam de ajuda internacional. Em contrapartida, para este autor o termo "exilado" encontra-se aliado a uma certa espiritualidade e marcado pela ideia de solidão.

A vivência do casal Ostrakoff em Xangai denota uma vertente ainda dourada do exílio, com Igor a gerir com sucesso o "Hotel de Paris", que converte em bordel de luxo, enquanto corre a década de trinta, e mais uma vez eles vivem na margem privilegiada da cidade, alheios à miséria que grassa e à instabilidade política:

Cegos em Xangai!

Tão cegos como em Paris, tão cegos como em Odessa.

Encerrados no seu pequeno mundo, artificial e brilhante, absorvidos num quotidiano de lucros fáceis, compromis- 
sos sociais e pequenos escândalos, os privilegiados daquela sociedade fechada cerram os olhos e parecem ignorar a tempestade que lavra à sua volta, no país imenso, e mais perto, já portas a meias, naquele outro mundo da cidade chinesa de bairros fétidos onde reinam as tríades, a corrupção, a prostituição, a droga, a miséria. (CARVALHO, 2015, p. 155)

Emerge novamente a crítica irónica ao alheamento face ao meio circundante de uma classe ainda privilegiada, alicerçada numa futilidade que depressa se desmoronará com a agitação social: "Para os tai-pans, e outros kuai-lous menores, seguros numa arrogante extraterritorialidade e no seu próprio policiamento municipal, "aquilo" era cor local. Os "chinas", de resto, tinham sido sempre assim!" (CARVALHO, 2015, p. 155). Neste caso, o narrador utiliza dois termos em chinês (cantonês) que designam, no primeiro caso, os homens de negócios ocidentais (tai-pans $)^{5}$ e no segundo (kuai-lous), de forma pejorativa, os estrangeiros brancos. Este uso dos termos cantoneses revela uma proximidade face à comunidade chinesa e uma crítica à arrogância dos estrangeiros ocidentais, com a repetição da expressão "tinham sido sempre assim".

Por sua vez, em $A$ Mãe, constatamos que Xangai, apesar de tudo, será também o local de exílio onde as personagens adquirem alguma qualidade de vida. À semelhança do que sucedeu com Irina, também o contexto familiar de Natasha é narrado, servindo de enquadramento e de justificação para o seu temperamento corajoso, destemido, frontal, que contrasta fortemente com a delicadeza e a fragilidade de Irina. Nesta sequência, é-nos revelado que Natasha é filha de Ivan Korbachenko, um sargento do Exército Imperial de Moscovo, que jurara fidelidade ao "Czar de todas as Rússias", cujo regimento foi destacado para a fronteira sueste da Sibéria. É nessa cidade que, já com idade avançada, casa e nasce Natasha, cuja máe morre de parto. Embora tenha em comum com Irina o facto de ter ficado órfá de mãe, ao contrário do que sucede com a primeira, oriunda de uma aristocracia requintada, Natasha é educada num ambiente modesto, de cariz militar, pois "[...] sobreviveu ao frio, à falta de ternura de

5 Este termo foi divulgado para o exterior da China, após a publicação do conto The Taipan de Somerset Maugham (1922) e do romance de James Clavell, Tai-pan (1966). 
mãe, aos cuidados canhestros do pai, à rudeza convivial dos contrabandistas, às agruras da vida numa povoação de fronteira, na orla da floresta daquele Far East remoto e gelado." (CARVALHO, 2001, p. 24). Aos dez anos, Natasha começou a gerir a casa e a taberna do pai, habituando-se desde cedo a assumir responsabilidades. Quando a revolução bolchevista ocorre, Korbachenko é preso e a casa incendiada, e Natasha foge com a arma do pai e a roupa que leva no corpo. Sozinha no mundo, enfrenta corajosamente os inúmeros perigos que se lhe deparam na árdua jornada, sendo aos quinze anos violada por um Oficial do Exército, que ela castra com um tiro. A seguir, também Natasha desagua em Xangai. Perante o turbilhão da "Paris do Oriente"

[...] sente-se envergonhada da sua figura de camponesa rústica e ignorante, de mulher de fronteira, sólida de formas e rude de maneiras [...] era apenas uma rapariga pouco letrada [...] mais habituada ao cálculo do preço do repolho do que à meditação das grandes dúvidas existenciais (CARVALHO, 2001, p. 47-48).

Então, conhece Rachel, uma estudante russa, com quem partilha o quarto, e que a inicia na "mais velha profissão do mundo". Voluntariza-se para trabalhar no Hotel de France, dirigido por Ostrakoff, mas este a rejeita. Emergem, assim, os primeiros contornos da "comédia humana" "através do encontro entre os casais que protagonizam os dois romances. Passados três anos, Natasha volta a candidatar-se ao "Café De Paris", que integra o Hotel de France, gerido por Ostrakoff, e é admitida como empregada de mesa. Neste ponto, ocorre o contacto entre as personagens principais dos dois romances. Em $A$ Mãe, é resumido o contexto que levou os Ostrakoff àquela situação. A devoção mostrada por Irina ao marido, apesar do comportamento leviano e boémio deste, inspiram a compaixão de Natasha que lamenta: "Pobre Senhora Ostrakoff?" (CARVALHO, 2001, p. 36). Após cinco anos a trabalhar como empregada de mesa e

6 La Comédie Humaine foi o título conferido pelo escritor francês Honoré de Balzac (17991850) ao conjunto da sua obra, composta por cerca de 88 títulos, sobretudo romances, novelas e contos. Na sua tentativa de renovar o romance e de caracterizar de forma completa a sociedade da sua época, Balzac cria um mecanismo textual baseado na reaparição das mesmas personagens nas diversas narrativas. 
sing song girl, Natasha abandona o emprego devido a um desentendimento com Igor, revelando o seu carácter voluntarioso e insubmisso. A representação da discussáo entre ambos é feita com o recurso da reprodução de insultos que misturam o francês e o russo: "Gavno, Monsieur Ostrakoff” (CARVALHO, 2001, p. 79). A utilização de expressôes em diversas línguas (russo, inglês, francês, cantonês...) também confere verosimilhança às narrativas. Tal como preconiza Hamon (1982, p. 141), "à la limite, le réel n'est plus qu'uue mosaique linguistique". As mais diversas manifestaçôes dos idiolectos são reproduzidas no texto contribuindo para lhe atribuir também uma "verdade ficcional" (RIFFATERRE, 1990).

Por seu turno, evidencia-se o alívio de Natasha por já não ter de se submeter a Ostrakoff e "A toda uma máquina social, inabalável, intransigente e implacável, que a condenava a um destino que ela repudiava" (CARVALHO, 2000, p. 81). No fundo, este pensamento reforça a coerência interna da personagem, que embora se tenha de desviar, por vezes, de alguns dos seus princípios por necessidade, procura manter-se fiel às suas linhas de conduta. De seguida, no restaurante "Au Petit Bistrot", onde começa a trabalhar, ela conhece Vassili Yakovitch, "estudante-operário e compatriota", filho de um alfaiate judeu também forçado ao exílio devido à revolução bolchevista. Acabam por casar, sendo, também neste caso, elaborada uma análise psicológica das personagens que enfatiza os seus fortes contrastes, sublinhando-se a fragilidade de Vassili e a sua fraca determinação, que se situam nas antípodas da forte personalidade de Natasha, aliás reforçada também pela sua caracterizaçáo física marcada pela robustez. Após inúmeras dificuldades, Vassili consegue um emprego como professor no Instituto Politécnico de Xangai e têm cinco filhos. Tal como em Requiem para Irina Ostrakoff, também aqui o início da invasão japonesa e da Guerra entre a China e o Japão náo perturbam a vida serena dos expatriados residentes nas zonas internacionais, visto que

[...] o sofrimento e a miséria das massas chinesas passavam-se lá muito longe, na cidade china, os massacres só eram conhecidos através dos periódicos [...] e as campanhas militares transformavam-se em exercícios intelectuais de envolvimentos e logísticas. (CARVALHO, 2001, p. 129). 
Perante tal cenário, a situação de apátrida (embora a União das Repúblicas Soviéticas também não estivesse envolvida na guerra) era uma vantagem para os Yakovitch, o único privilégio de "[...] não se ter identidade nacional nem compromissos patrióticos reconhecidos". (CARVALHO, 2001, p. 131). Porém, iniciam-se as perseguições contra os judeus, e a família foge com destino ao "[...] pequenino enclave no sueste Chinês ainda poupado, pela frágil neutralidade portuguesa, à loucura e ao horror daquela guerra monstruosa e sem quartel." (CARVALHO, 2001, p. 132). Antes da partida para o novo exílio de Macau, é ainda relatado um irónico reencontro entre Natasha e Igor Ostrakoff, em que esta exibe o seu novo estatuto social como esposa de um professor universitário e vai tomar um chá ao Café de Paris.

Não obstante, os breves esboços de uma "comédia humana" nâo se restringem a este encontro entre as personagens principais das duas obras cujos destinos futuros terão semelhanças. Há outras personagens em comum, nos dois romances, que servirăo como adjuvantes nas acções, assumindo-se como conectores dos destinos das protagonistas: Big Bertha, uma refugiada russa que se dedica à prostituição em Macau e que tentará apoiar, na medida das suas possibilidades, tanto Irina como Natasha; Monsieur Dêdé, ou seja, Monsieur Desirée Dieudonné, proprietário dos hotéis onde Igor trabalha, que, como refere Seabra Pereira, "aproxima-se da figura pícara e como tal contribui para a comédia humana do romance (CARVALHO, 2015, p. 321). Ele é caracterizado como "Rotundo, exuberante, bonacheirão, de bigode farfalhudo e olhar brejeiro, dado ao conhaque e às damas" (CARVALHO, 2015, p. 140). Esta personagem confere comicidade ao discurso - aliás, a ironia e o sentido de humor perpassam a escrita de Leal de Carvalho. Um exemplo disso é a referência de que Desirée - que vive entre Oriente e o Ocidente - sentiu-se incomodado com a guerra porque "[...] o obrigara a interromper as suas visitas regulares a Paris, onde vinha a banhos de civilização e cura das águas [...] na ronda assídua dos bistros e brasseries da capital" (CARVALHO, 2015, p. 140).

Outra personagem comum é Cynthia Salles, de nacionalidade portuguesa, mas funcionária do Consulado Britânico, companheira de viagem na travessia de Natasha e da família para Macau, e em Requiem apoia Irina na fase final, dando-lhe acesso ao Consulado 
Britânico (onde ela acaba por falecer) e tenta ajudá-la a recuperar o estatuto social perdido na desventurada existência de refugiada apátrida. Também Cynthia é descrita como dotada de peculiaridades que a destacam e lhe atribuem um tom cómico: "[...] a estatura atarracada, o carão feio e simpático, [...] a gargalhada rouca um tanto máscula e [...] o mesmo charuto fumado com visível prazer e gostoso deleite" (CARVALHO, 2015, p. 285). Outros elementos relevantes no apoio aos refugiados são o Padre Percival, homem generoso, que trabalha na Assistência e que, em ambos os romances, incentiva as protagonistas a pedirem o visto de entrada nos Estados Unidos, alimentando-lhes o sonho americano, como modo de escapar à miséria, e a Irmã Benvinda, freira hospitalar, que trabalha no hospital onde Irina é internada após a tentativa de suicídio, e onde falecerá Ivan, o filho de Natasha. Embora muito distante das dimensôes da "comédia humana" de Balzac, a presença destas personagens reforça a verosimilhança dos romances e aconfiguração de Macau como um local alcandorado no sueste da China, caracterizado pela coexistência de mundos e de culturas, transparecendo o objectivo "de compor um painel polifacetado de humanidade característica” (PEREIRA, 2015, p. 321).

\section{Na outra margem: reconstruções identitárias no espaço de exílio}

A descrição da dura travessia de Irina e Igor para Macau revela uma nova dimensão das personagens na qual adquirem um sentido de solidariedade e de partilha com o "Outro". Manifesta-se, pela primeira vez, a empatia com o drama dos outros, os companheiros de viagem, como se as fronteiras da alteridade se tivessem atenuado devido a uma partilha do drama vivencial comum: "Como eles, sentiam-se tomados de angústia pelo futuro desconhecido, à deriva, como órfãos da Humanidade, eles mais órfãos do que os outros, porque sem pátria, sem papéis, sem família, sem outro amparo que não fosse um e outro" (CARVALHO, 2015, p. 165). Emerge o drama dos apátridas e todas as implicaçóes da "perda de uma pátria" na desconstrução e reconstruçáo identitária. Esta ideia vai ao encontro das reflexôes de Hannah Arendt (2009, p. 324-325), ao referir que "Os apátridas estavam tão convencidos quanto as minorias de que a 
perda de direitos nacionais era idêntica à perda de direitos humanos e que a primeira levava à segunda”. Com efeito, esta conexão entre a identidade e o sentido de pertença a uma nação é também salientada por Leerssen (2006, p. 229) ao afirmar:

Nationality lies, if anywhere, with the people's own sense of identity,their self-identification, and no single circumstance can directly determine that collectiveattitude (Renan speaks of 'un principe spirituel, un état d'âme'): nationality is a stateof mind.

$\mathrm{Na}$ verdade, perdida a nacionalidade, as personagens sofrem um processo de perda instauradora de uma fissura identitária. Neste contexto, como afirma Stuart Hall, a "nação não é apenas uma entidade política mas algo que produz sentidos - um sistema de representação cultural" (HALL, 2006, p. 49). Além disso, para Benedict Anderson (1983), a identidade nacional é uma comunidade imaginada cujos traços distintivos residem nas formas diversas como as sociedades são imaginadas. Neste caso, quando o país de origem das protagonistas se encontra em plena reconfiguração e elas são atiradas para a outra margem, para o exílio, a capacidade de imaginar a nação é substituída pela incerteza, pelo vazio dessa existência à qual, sendo apátridas, deixaram de pertencer.

Também em $A$ Mãe, Natasha e a família fazem a travessia nas condiçóes precárias da segunda classe para Macau. Entre os refugiados destaca-se, como já referimos, Cynthia Salles que, afável e conversadora, tenta espalhar optimismo à sua volta, demonstrando a confiança na proteção do Governo - o que não convence Natasha, que se interroga: "Mas para ela e para a família que não tinham passaporte? E quem não tem passaporte, não tem pátria. Sem papéis, não se é ninguém, não se existe [...]" (CARVALHO, 2001, p. 137-138). Estas preocupaçóes de Natasha adquirem sentido no momento da chegada a Macau, quando são separados dos restantes refugiados devido à ausência de documentos - refere-se que a situação dos apátridas era frequente já que: "Macau estava cheia de refugiados das mais variadas províncias da China, de países do Sueste Asiático e outros, fugidos às fomes e à guerra, europeus de múltiplas nacionalidades, de Hong Kong e de Xangai, todos à procura de abrigo". (CARVALHO, 2001, 
p. 140). No entanto, apesar de o estatuto de apátridas corresponder a "uma lepra política ou social que os segregava" (CARVALHO, 2001, p. 140), em Macau, isso não implicava a sua expulsão, pois fora adoptada "[...] uma política benevolente, se não quixotesca, de cidade aberta, mas privava-os da precária assistência assegurada pelo Governo aos refugiados de nacionalidade portuguesa". (CARVALHO, 2001, p. 142). Assim, Macau é concebida como "[...] o porto de abrigo onde, na esperança de um pouco de paz e felicidade, desembocava a humanidade em fuga à loucura que avassalava o mundo" (CARVALHO, 2001, p. 144). Com efeito, embora tenha escapado à guerra devido à sua neutralidade, sofreu as suas consequências, pois a população duplicou subitamente de 200.000 pessoas para quase meio milhão (BOTAS, 2012, p. 25).

Em ambos os romances, constatamos que a primeira atitude das personagens, na nova terra de exílio, é a procura dos conterrâneos com quem poderiam sentir afinidades a nível linguístico, cultural e identitário. Por outras palavras, buscam-se aqueles com quem se torna possível a partilha de memórias, pois só através das memórias poderemos encontrar de forma segura o nosso lugar no mundo, sendo a amnésia um elemento destrutivo da identidade. Assim, em Requiem para Irina Ostrakoff, Igor estabelece contatos com a pequena comunidade russa, apátridas como eles, que desaguaram em Macau e que haviam conseguido instalar-se nos bairros sociais da Assistência. São, deste modo, narradas as condiçóes precárias de sobrevivência que determinam, de forma verossímil e coerente, relaçôes interpessoais marcadas pela ambiguidade, contraditórias:

Esquecem-se barreiras sociais do passado - é largo e espectro social dos refugiados sem pátria - e vivem como podem; ajudam-se guerreiam-se, amam-se, odeiam-se.

Mas quando, mais tarde, nas noites frias do curto Inverno macaense ou nas quentes e húmidas do longo período estival, Igor agarrava na balalaika que salvara e cantara cançóes russas no seu quente barítono, ainda envolvente, os outros refugiados juntavam-se-lhe, faziam coro espontaneamente e recreavam por uns breves momentos, naquela little Russia de gheto, uma saudade da Pátria tão distante, tão presente, tão viva, tão perdida [...] (CARVALHO, 2015, p. 170-171). 
Verificamos, através do excerto supracitado, que a partilha do mesmo passado revela-se essencial, a consciência histórica assume-se como raiz, por conseguinte, os grupos marginalizados (como, neste caso, os russos apátridas) têm necessidade da partilha de um passado comum, das tradiçóes, de cultivar e comungar uma identidade histórica que alimente o sentido de pertença. Nesta sequência, como afirma Leerssen (2007, p. 336), "[...] foundational episodes and crises in the nation's past take on mythical meaning; in the permanence of their memory they establish a continuity between past and present which is properly identitarian". Esta continuidade entre o passado e o presente é táo relevante em termos individuais como colectivos. Tal como referiu Bhabha (1990, p. 11), "Nations, like narratives, lose their origins in the myths of time and only fully encounter their horizons in the mind's eye".

Deste modo, perdida a "nacionalidade", o horizonte que resta apenas pode ser captado pelo olhar da mente, através da evocação, das recordaçóes, da recriação de elementos tradicionais, como é o caso das cançôes e da música, consubstanciadas no canto de Igor com a sua balalaika. Também neste caso, a identidade é fruto de um contínuo confronto entre o sujeito e o seu ambiente, uma constante negociaçáo entre o "eu", o mundo e as experiências vivenciadas. É precisamente nesse processo de negociaçáo, numa tentativa de reencontro com a realidade familiar, que a identidade se vai articulando, sendo formada ao longo do tempo, como defende Hall, num processo inacabado, que permanece sempre incompleto (HALL, 2006, p. 38). Será, pois, o intuito de recuperarem a memória identitária de uma pátria perdida pela distância e pela situação de apátridas exilados que determina essa já anteriormente referida procura de raízes, numa tentativa de instaurar um sentido de pertença, de reforçar uma identidade com base nos elos entre o passado e o presente, restaurada através da música e da partilha de um património cultural imaterial comum.

Este encontro com os outros refugiados russos e a alusão aos refugiados oriundos de outros países configura Macau no que Brah (1996, p. 208) definiu como um "espaço de diáspora", ou seja, um ponto onde as fronteiras da inclusão ou exclusão, de pertença e alteridade do "eu" e do "outro", são contestadas. A ideia de certa contestaçáo implícita e de desafio encontra-se subjacente também 
na atitude dos residentes: "[...] a população local tolera-os com algum ressentimento: a fome abunda e os recursos locais são escassos" (CARVALHO, 2015, p. 171). De modo semelhante, em $A$ Mãe é referida "[...] a via dolorosa em busca dos conterrâneos, agrupados numa comunidade de desânimo e miséria." (CARVALHO, 2001, p. 147), pois só nessa comunidade:

[...] os Yakovitch podiam conversar na língua-mãe e até, de longe, em longe, naquela Little Russia, de gheto e de miséria, ouvir alguém cantar ao som de uma guitarra ou de uma balalaika uma Occhy Choernya , nostálgica, magoada e trágica, um hino de saudade às searas da Ucrânia, às neves da estepe, à pátria perdida e sempre presente. E isso era, no meio da mais desoladora pobreza, ainda um laço ao passado, à grande-mãe Rússia e à identidade nacional de que os burocratas do Kremlin os tinham arbitrariamente espoliado. (CARVALHO, 2001, p. 161-162)

Neste caso, é salientada claramente a tentativa de recuperação da identidade nacional que lhes foi extorquida. Emerge o nítido vínculo à pátria através da personificação "grande-mãe Rússia" e da alusão à língua-materna, elemento relevante na configuração identitária. Esta cisão com a pátria, com o país de origem, ferida aberta na alma dos exilados, será, por vezes, evocada ao longo dos romances. Além disso, em ambas as obras, tal como observa Seabra Pereira, aos protagonistas russos, "[...] o narrador julga oportuno atribuir valor de signos identitários da alma eslava a certos traços de comportamento ou reaçóes anímicas" (CARVALHO, 2015, p. 320). Nesta sequência, "à maneira do povo russo, Igor cantarolou a Ochernaya." (CARVALHO 2015, p. 172), uma canção típica do folclore russo. A Irina é atribuído temperamento triste e fatalista de eslava (CARVALHO, 2015, p. 102). Aliás, o fatalismo eslavo é um traço várias vezes evocado relativamente a Irina e comum a Natasha. No caso de Irina, é mencionada a "ansiedade eslava" (CARVALHO, 2015, p. 128), "o drama da existência é exacerbado pela sua sensibilidade eslava"; alude-se à "[...] natural reserva do seu temperamento eslavo que os anos de infortúnio mais tinham retraído" (CARVALHO, 2015, p. 232-256), acentuado-se o "atávico pessimismo eslavo" (CARVALHO, 2015, p. 167-168). 
Deste modo, as características atribuídas aos eslavos são estereotipadas, seguindo a tendência da imagem europeia do povo eslavo, referida por Naarden e Leerssen (2007, p. 229), caracterizada por "[...] the natural submissiviness, meekness, endurence and patience of Russia’s Slavic Population”. Assim, é veiculada a imagem de uma disposição temperamental ligada a uma moral antipragmática, meditativa e a um caráter místico. É deste modo elaborado um "etnotipo" constituído pelas características do povo eslavo que o distinguem dos outros povos, sendo instaurado o que Leerssen (2016, p. 17) denomina como o "effet de typique", ou seja, os traços considerados significativos susceptíveis de distinguir o temperamento ou a predisposição psicológica de um determinado povo (neste caso, o eslavo), explicando um perfil específico comportamental. Este etnotipo, a contrastar com o estatuto de apátridas, encontrar-se-á subjacente na configuração identitária de Irina e Natasha, que transportam em si "os cromossomas" do país de origem. Neste contexto, em ambas as obras, destaca-se a profunda análise psicológica das personagens que não obedecem à nítida "transparência" veiculada ao discurso realista (HAMON, 1982, p. 156). Por conseguinte, atentaremos sobretudo na configuração das duas protagonistas femininas, personagens dotadas de profunda coerência interna, ricas e densas, correspondentes ao que António Cândido (2005, p. 63) denominou (citando Foster) como personagens esféricas, que contêm em si a imprevisibilidade da vida, sendo capazes de nos surpreender de forma convincente, e que, na mesma linha de pensamento, podemos considerar que são submetidas "a uma caracterização relativamente elaborada e não definitiva" (REIS; LOPES, 2011, p. 323).

Irina, da qual já salientámos a fragilidade e delicadeza, torna-se cantora no bar dirigido pelo marido e envolve-se numa breve aventura amorosa com o empresário macaense Tarcísio Guterres, que a traumatiza por ter traído "a sacrossantidade do matrimónio", mesmo tendo sido impelida a isso pelo leviano e boémio Igor. Esse trauma é atribuído à sua educação ferozmente tradicionalista e conservadora e à "melancolia eslava” (CARVALHO, 2015, p. 224-225). Após um novo regresso a Xangai, terminada a guerra em 1945, eclode a revolução comunista e Irina volta novamente para Macau, onde acaba por ficar sozinha, após a partida de Igor para a Nova Caledónia. Nesta 
última fase do exílio ainda mais dura devido à solidão, Irina tenta realizar vários trabalhos, como por exemplo ajudar o padre Percival na assistência aos refugiados, mas a sua inépcia e incompetência são notórias. É nessa fase que ocorre a verdadeira "descida aos infernos" ao receber a notícia de que Igor refazia a vida com outra mulher que a conduz a uma tentativa de suicídio. Então, posteriormente, já recuperada, transparece toda a crise identitária que a dilacerou, ao longo da obra, e a sua preocupação com a respeitabilidade e o sentido de pertença: "Suspeitava ter herdado dos avós essa consciência aguda da propriedade das atitudes, da correcçáo de maneiras, dos comportamentos sociais adequados. E parecia-lhe cruel ironia que toda a vida de refugiada se apostara em lha negar." (CARVALHO, 2015, p. 291). Assim, o insignificante e esporádico trabalho que lhe é proporcionado por Cynthia, nos consulados, é essencial para Irina se reafirmar como ser humano, "[...] rejeitar a marginalização social dos refugiados, a necessidade de pertencer ao seu meio, ao meio a que se sentia com direito" (CARVALHO, 2015, p. 292).

Por seu lado, em $A$ Mãe, Natasha tenta preservar a sua dignidade, lutando pela sobrevivência e com a impossibilidade de encontrar emprego. Embora agnóstica, acaba por se refugiar numa igreja onde se questiona se não haverá um Deus para os refugiados, para os sem pátria (CARVALHO, 2001, p. 154). Além disso, apesar do seu carácter forte e duro, assistimos a momentos de inesperada ternura, que no entanto não lhe ameaçam a consistência nem a verossimilhança, tornando-a antes mais humana. Uma importante cisão identitária ocorre quando se vê forçada a lançar a filha no mundo da prostituição, como única forma de garantir a sobrevivência da família: "Cansada de lutar para garantir a sobrevivência de todos. Cedeu e qualquer coisa dentro dela pareceu morrer." (CARVALHO, 2001, p. 172). Espelha-se a vergonha e o constrangimento de Natasha por ter de fazer à filha Ludmila uma proposta tão indigna, "Mas a família tinha de sobreviver para poderem ir para a América" (CARVALHO, 2001, p. 174). O sonho do Eldorado americano acalenta a protagonista, servindo como motivação para enfrentar as duras provaçóes de que é vítima. Contudo, a situação mais dramática no seu percurso - depois de ter impedido o suicídio do marido, Vassili - coincide com o modo como é solucionado o grande dilema que a avassala, no últi- 
mo capítulo do romance. Terminada a guerra, chega autorização de entrada nos Estados Unidos para todos os membros da família, exceto para Ivan por ser deficiente mental. Instaura-se o dilacerante dilema: devem desistir do sonho americano, única hipótese de escapar à miséria? Ou abandonar Ivan em Macau? Natasha recusa terminantemente abandonar o filho. A grande questão ética da protagonista, no final, é resolvida de forma inesperada, mas verossímil, como fruto de todo a saga infernal empreendida, ao longo da narrativa, e da impossibilidade de enfrentar os custos que a sobrevivência de Ivan implicaria. Então, é figurada uma situação-limite do mais profundo sofrimento em que Natasha acompanha Ivan no hospital, e, durante uma grave crise de asma, o abraça e não lhe consegue dar o comprimido que lhe poderia salvar a vida: "Se ele morresse assim, nesse mesmo momento, não sofreria mais [...]. Afinal seria melhor assim [...] O sofrimento seria todo para si que tanto lhe queria [...]. Seria ela a suportar pela vida fora a saudade e a culpa [...]" (CARVALHO, 2001, p. 213). É a ideia do sacrifício individual em detrimento do bem comum que aflora, num relato impregnado de dor e de humanismo.

\section{Considerações finais}

Em suma, ultrapassando os paradigmas clássicos do romance realista do século XIX, Rodrigo Leal de Carvalho constrói dois romances que dialogam entre si, não apenas através do reaparecimento de algumas personagens, mas sobretudo através da criação da verosimilhança instauradora de uma "verdade ficcional" (RIFFATERRE, 1991), que ultrapassa as próprias fronteiras do real. Aliás, as personagens criadas parecem feitas de carne e osso, pois comunicam "a impressão da mais lídima verdade existencial" (CANDIDO, 2005, p. 55). Nesta esteira, tal como é corroborado por Seabra Pereira (2015, p. 315-316),

[...] num meridiano de fragilidade e desventura acatada, Irina torna-se figura inesquecível para o leitor, ironicamente táo impressiva na sua branda personalidade que só a voluntariosa Natasha de $A$ Mãe poderá vir disputar-lhe a primazia nessa galeria de personagens a que o autor dá vida imperecível. 
São estas vidas e todo o seu percurso de refugiadas apátridas que constituem a pedra angular das narrativas, cuja consistência comunga de alguns dos procedimentos comuns ao romance realista, intercaladas com reflexôes irónicas, críticas e impregnadas de um subtil sentido de humor. É através dum discurso dinâmico, conciso - embora a subjectividade do narrador irrompa com alguma frequência - que é representada a saga das personagens e o caleidoscópio social e histórico no seio do qual se vão forjando as identidades. Neste contexto, se o reaparecimento de personagens de umas obras para as outras visa uma recriação da dinâmica social, o recurso a expressóes noutras línguas pretende recriar a diversidade linguística existente em Macau, esse porto de abrigo quixotescamente aberto aos povos que tudo perderam, desde à pátria à dignidade. Embora o tempo histórico se localize no século XX, as obras não podiam ser mais actuais no mundo de hoje, em que, como referiu Allison Jeffers (2012, p. 15), "[...] thinking ethically about refugees begins with hospitality and responsibility for the other". Aliás, foi essa a lição de Macau, esse único e diminuto espaço neutral num extremo oriente dilacerado pela guerra, que salvou a vida a milhares de pessoas, encerrando em si "o segredo de uma história secular onde a cidade foi não só um oásis de paz, mas também um teatro de guerra” (BOTAS, 2012, p. 25). É esse testemunho de sobrevivência no âmago da mais desumana miséria, mas também de solidariedade, humanismo e de resiliência, que Leal de Carvalho transmite nas suas narrativas, dando voz aos apátridas refugiados, silenciados e perdidos entre os novelos da História. $\mathrm{Na}$ verdade, as Irinas e as Natashas continuam por aí, tentando escapar dos mais diversos infernos em frágeis barcos, cruzando fronteiras, mundos e culturas.

\section{Referências bibliográficas}

ANDERSON, Benedict. Imagined Communities. Reflections on The Origin and Spread of Nationalism. Londres/Nova Iorque: Verso, 1983.

ARENDT, Hannah. Origens do Totalitarismo. São Paulo: Companhia das Letras, 2009. 
BHABHA, Homi (ed.). Nation and Narration. Londres e Nova Iorque: Routledge, 1990.

BLAYER, Irene Maria F.; GAGO, Dora Nunes. Espaços e estórias na obra de Rodrigo Leal de Carvalho: Encontro com o escritor. InterDisciplinary Journal of Portuguese Diaspora Studies, 5, 2016, p. 111-124.

BERSANI, Leo. Le réalisme et la peur du désir In: BARTHES, R. et al. Littérature et Realité. Paris: Ed. du Seuil, 1983, p. 47-80.

BOTAS, João F. O. Macau (1937-1945). Os Anos da Guerra. Macau: Instituto Internacional de Macau, 2012.

BRAH, Avtar. Cartographies of Diaspora. Contesting Identities. London and New York: Routledge, 1996.

BROOKSHAW, David. Perceptions of China in Modern Portuguese Literature: Border Gates. Lewiston, N.Y.: The Edwin Mellen Press, 2002.

CANDIDO, António. A personagem do romance. In: Cândido, A. et al (Org.). A personagem de fiç̧ão. $11^{\mathrm{a}}$ ed. São Paulo: Perspectiva, 2005, p. $53-80$.

CARVALHO, Rodrigo Leal de. Requiem para Irina Ostrakoff. $3^{\text {a }}$ ed. Macau: Livros do Oriente, 2015.

. A Mãe. Macau: Livros do Oriente, 2001.

FULFORD, Robert. The Triumph of Narrative. Storytelling in the Age of Mass Culture. New York: Broadway Books, 1999.

JEFFERS, Alison. Refugees, theatre and crisis. Performing global identities. London: Palgrave, Macmillan, 2012.

HALL, Stuart. A identidade cultural na pós-modernidade. Tradução Tomás Tadeu da Silva, Guacira Lopes Louro. 11. ed. Rio de Janeiro: DP\&A, 2006.

HAMON, Philip. Un discours contraint. In: BARTHES, R. et al. Littérature et Realité. Paris: Ed. du Seuil, 1982, p. 119-181.

LABORINHO, Ana Paula. Notas para um Requiem. In CARVALHO, Rodrigo Leal de. Requiem para Irina Ostrakoff. $3^{\mathrm{a}}$ ed. Macau: Livros do Oriente, 2015, p. 9-18.

LEERSSEN, Joep. National Thought in Europe. A Cultural History. Amsterdam: University Press, 2006.

. Identity/Alterity/Hibridity. In: BELLER, Manfred; LEERSSEN, Joep. Imagology, the cultural construction and literary representation of characters. Amsterdam, New York: Rodopi, 2007, p. 335-341. 
LEERSSEN, Joep. Imagology: On using ethnicity to make sense of the world. In: GALEOTE, Géraldine (coord.). Ibéric@l. Revue d'études ibériques et ibéro-américaines. Dossier monographique: Les stéréotypes dans la construction des identités nationales depuis une perspective transnationale. 10, 2016, p. 13-31.

NAARDEN, Bruno; LEERSSEN, Joep. Russians. In: BELLER, Manfred; LEERSSEN, Joep. Imagology, the cultural construction and literary representation of characters. Amsterdam, New York: Rodopi, 2007, p. 226-229.

PEREIRA, José Carlos Seabra. O Delta Literário de Macau. Macau: Instituto Politécnico de Macau, 2015.

RIFFATERRE, Michael. Fictional Truth. Baltimore and London: The Johns Hopkins University Press. 1990.

REIS, Carlos; LOPES, Ana Cristina. Dicionário de Narratologia. Coimbra: Livraria Almedina, 1991.

SAID, Edward. Reflexóes sobre o exílio e outros ensaios. Trad. de Pedro Meira Soares. São Paulo: Companhia das Letras, 2003.

SENA, Maria Tereza. Carvalho, Rodrigo Leal de. Ditema, Dicionário Temático de Macau. Vol I. Macau: Ed. Espadinha, Maria Antónia e Universidade de Macau, 2010, p. 276-277.

Dora Nunes Gago é Doutora em Línguas e Literaturas Românicas Comparadas e Mestre em Estudos Literários Comparados pela Universidade Nova de Lisboa (Portugal) e Licenciada em Português e Francês pela Universidade de Évora (Portugal). Foi Leitora do Instituto Camóes no Uruguai, investigadora de pós-doutoramento na Universidade de Aveiro (Portugal) e visiting post-doc. scholar na Universidade de Massachusetts Amherst (Estados Unidos). É professora Associada de Literatura no Departamento de Português da Universidade de Macau (China) e, atualmente, é Vice-directora desse departamento e Coordenadora dos cursos de pós-graduação. É ainda colaboradora do Centro de Línguas e Culturas (Universidade de Aveiro), CHAM e CETAPS (Universidade Nova de Lisboa) e LIA (Laboratório de Interlocuçóes Asiáticas) da Universidade de São Paulo. E-mail: doragago@um.edu.mo

Recebido em: 16/01/2018

Aceito em: 15/07/2018 